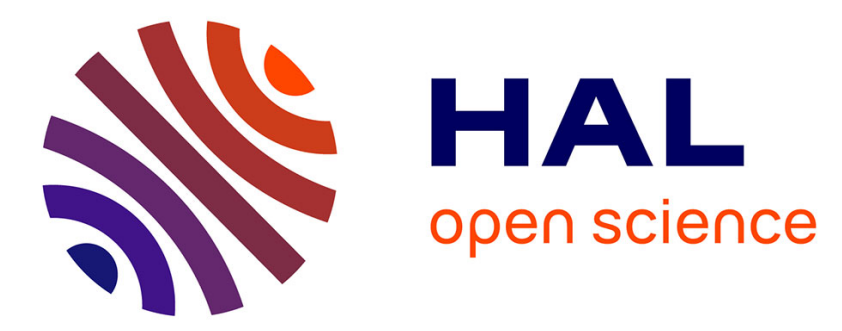

\title{
Study of Ground Treatment on Improvement of Pile Foundation Response in Liquefiable Soils
}

\author{
Chen Yulong
}

\section{To cite this version:}

Chen Yulong. Study of Ground Treatment on Improvement of Pile Foundation Response in Liquefiable Soils. Mechanics, Materials Science \& Engineering Journal, 2016, 10.13140/RG.2.1.2504.0140 . hal01325258

\section{HAL Id: hal-01325258 \\ https://hal.science/hal-01325258}

Submitted on 2 Jun 2016

HAL is a multi-disciplinary open access archive for the deposit and dissemination of scientific research documents, whether they are published or not. The documents may come from teaching and research institutions in France or abroad, or from public or private research centers.
L'archive ouverte pluridisciplinaire HAL, est destinée au dépôt et à la diffusion de documents scientifiques de niveau recherche, publiés ou non, émanant des établissements d'enseignement et de recherche français ou étrangers, des laboratoires publics ou privés. 


\title{
Study of Ground Treatment on Improvement of Pile Foundation Response in Liquefiable Soils
}

\author{
Chen Yulong 1, a
}

\author{
1 - Department of Civil Engineering, The University of Tokyo, Tokyo 113-8656, Japan \\ $\mathrm{a}-\underline{673054399 @ q q . c o m}$
}

DOI 10.13140/RG.2.1.2504.0140

Keywords: liquefaction, pile, ground treatment, retrofitting countermeasures.

\begin{abstract}
In light of the disastrous the 2011 Tohoku Pacific Earthquake, the government of Japan has conducted studies to revise the seismic design code, and elevated peak ground accelerations have been adopted. Consequently, revisions on existing design to comply with the updated code are required for public projects that are still undergoing. The design safety needs to be reassessed, and implementation of strengthening measures is required if deemed necessary. For liquefaction countermeasures, ground treatment techniques that could increase the density of soils are often the preferable alternatives. The treatment usually increases the in-situ SPT-N or CPT- $\mathrm{q}_{\mathrm{c}}$ values, which in turn would increase the resistance of soil against liquefaction. For many public infrastructures in Japan supported by bored piles embedded partly or entirely in sandy soils, reevaluation of design safety against soil liquefaction would be required. In an assessment of possible retrofitting countermeasures for an infrastructure foundation, ground treatment has been considered. In this case study, effect of ground treatment on response of piles in liquefiable soils was investigated with numerical analyses using FLAC. Results provide insights into this ground treatment effect and useful information for consideration in future design or decision making.
\end{abstract}

Introduction. The 2011 Great East Japan Earthquake, with a magnitude of $M_{w}=9.0$, occurred in the Pacific Ocean about $130 \mathrm{~km}$ off the northeast coast of Japan's main island on March 11, 2011. The hypocentral region of this quake was about $500 \mathrm{~km}$ in length and $200 \mathrm{~km}$ in width. The quake was followed by a huge tsunami that destroyed many cities and killed and injured many people along the Pacific Coast. The numbers of dead and missing persons as of July 11, 2012 were 15867 and 2909, respectively. The tsunami broke the emergency cooling system of a nuclear power plant in Fukushima Prefecture, and large areas of Japan have been plagued by radiation and a shortage of electricity ever since. In the geotechnical field, many houses and lifelines were damaged by soil liquefaction, landslides occurred, dams failed and river dikes settled not only in the Tohoku district of northeastern Japan, but also in the Kanto district, which surrounds Tokyo. Liquefaction occurred over a wide area of reclaimed lands along Tokyo Bay, although the epicentral distance was very large, about 380-400 $\mathrm{km}$.

During the 2011 off the Pacific Coast of Tohoku Earthquake, soil liquefaction caused extensive damage to residential lands and houses, as well as to infrastructures, such as roads, rivers, ports, and water supply/sewage systems, over a wide area along the Pacific Coast in Tohoku and in Kanto, including the Tokyo Bay area. Due to the large fault zone, the duration of the strong shaking was extremely long. According to Tokimatsu et al. [1], liquefaction induced damages in Urayasu City such as sand piping on ground surfaces and significant ground subsidence resulting in buildings settlement, tilt, and lateral movement from $3 \mathrm{~cm}$ to $45 \mathrm{~cm}, 2^{\circ}$ to $3^{\circ}$, and $1 \mathrm{~cm}$ to $20 \mathrm{~cm}$, respectively, were recorded.

Most of the foundations of major infrastructures located on eastern Japan are composed of pile foundations. Because the surface soils in this area are primarily alluvial with characteristics of composition, dense/loose extents and ground water levels prone to liquefaction during earthquake, it is obvious that a pile foundation situated in this area is subject to high risk of failure when liquefaction 
occurs. The consequences may cause collapse of the superstructure. To avoid the damage of pile foundation and associated superstructure situated at the liquefaction-prone soil layers, prevention measure should be implemented in planning, design and construction, while one of the methods that have been widely applied in practice is ground treatment.

This paper presents a potential to approach determine and evaluate the range of ground treatment in practice and the verification of the effectiveness of ground treatment with the behavior of the pile foundation.

Methodology. The causes of liquefaction in sandy soils can be grouped into two categories: internal and external. The internal factors include soil density, fine contents, permeability, etc., while the external factors are related to the scales and durations of earthquakes. Liquefaction countermeasures can be developed in accordance with these two aspects and specific characteristics of local ground condition. Most of the current practices use SPT-N value (i.e. [2], [3], [4]) or CPT- $q_{c}$ value (i.e. [5], [6]) as baselines for evaluating the liquefaction potential. These baselines reflect the loose or dense extent and fine content of the ground soils of interest in which the denser the subsoil, the greater the values of these baseline factors and the lower the liquefaction potential. In gravel soils, liquefaction is in essence a function of void size and the properties of material filled-in rather than the above baseline factors. Thus, the direct use of the SPT-N value or the CPT- $\mathrm{q}_{\mathrm{c}}$ value in evaluating the liquefaction potential of gravelly soils is inappropriate.

During liquefaction, the lateral resistance of the pile decreases and may result in significant lateral deformation. In some cases, buckling failure may also occur. To minimize the lateral resistance reduction and lateral deformation of pile foundations in such a way that the risk of buckling failure can be controlled or avoided, the ground treatment methods, such as low pressure grouting, high pressure grouting, compaction grouting and dynamic compaction, are usually adopted in practice. The liquefaction potential can be reduced by increasing the densification extent or shear strength of the soils.

While the liquefaction of sandy soils occurs during an earthquake, the lateral earth pressure acting on the pile foundation decreases significantly as the effective stress reduces to zero, and the pile foundation will reach the maximum lateral deformation. With the dissipation of the excess pore pressure, the effective stress will recover and the soil will regain its shear strength. Nevertheless, this strength will not be the same as the one before the liquefaction. This recovered strength is generally termed the residual strength and can be estimated by using the reduction factor [7]. Results of centrifuge tests indicated that the liquefied fine sand has a residual strength of about 10 percent of the initial $p-y$ curve resistance, and other soil types with less liquefaction potentials are expected to have higher residual strength values [8].

Finn (2015) [9] used centrifuge tests to develop a dimensionless degradation parameter $\mathrm{Cu}$, which was a multiplier to reduce the load $p$ on $p-y$ curves developed for piles in sand under static conditions to account for excess pore water pressure effects. As can be seen in [9], $\mathrm{Cu}$ can be lower than 0.1 for high values of excess pore water pressure ratio. This implies that the residual $p-y$ resistance can be less than 10 percent of the initial resistance during liquefaction.

Turner (2016) [10] applied centrifuge model tests to develop the multiplier used for reducing the load $p$ of static $p-y$ curves for a single pile and to account for the effect of relative density on liquefaction potential. It shows that the valves of the multiplier are generally between 0.1 and 0.2 for fine sand at a relative density of about 35 percent, and between 0.25 and 0.35 for a relative density of about 55 percent, respectively.

To estimate the lateral deformation of the pile foundation during liquefaction, the strength parameters of the liquefied soil are subject to reduction because of the residual strength of the liquefied soil. The extent of the ground improvement can also be determined in such a manner. Assuming that the soils do not liquefy after appropriate ground improvement, the lateral deformation of the pile subjected to 
the same magnitude of earthquake should also be reduced. The amount of reduction depends on the strength of the improved soils.

Researches on the effects of ground treatment types, sizes, and locations showed that there were associated results for embankment. Zekri et al. (2015) [11] studied and reported the effects of improved ground sizes and locations on the performance of a section of the Highway I-57 bridge abutment. As shown from the results, the effect of the treatment size and location of an embankment underlain by a liquefiable soil layer indicate that a 24-m-wide treatment zone was most effective when it was located beneath the sloping portion of the embankment, as the treated zone location moves outward from beneath the sloping portion, predicted lateral displacement become progressively larger.

The impact of different treatment types on the performance of an embankment is illustrated by centrifuge test results from Huang and Wen (2015) [12] and summarized in Adalier et al. (1998) [13]. Adalier et al. (1998) [13] made several observations on the effectiveness of the various ground treatment methods on improving the performance of the embankment. If the intent of the ground improvement is to minimize lateral displacement and vertical settlement of the embankment, Adalier et al. (1998) [13] suggests that the available methods in order to decrease effectiveness are: (1) sheet piles with tie rods, (2) densification or gravel buttresses, and (3) cement-treated blocks, the latter the less effective. Cooke and Mitchell (1999) [14] showed that the reduction of liquefaction-induced ground deformations to acceptable levels may require more than one improvement type, and a particular type of improvement may be effective for only one target reduction (i.e. acceleration, deformation, or pore water pressure) but less effective in improving others.

The effect of the width of a densified sand zone on settlement of a supported shallow foundation structure was investigated using shaking table tests [15]. Results showed that for a given structure width, the increment of ratio of treatment zone width to structure width resulted in a decrease in the structure settlement ratio (measured settlement of structure divided by the liquefiable sand layer thickness).

The effect of treatment depth on response of a footing supported on a densified sand zone within a liquefiable sand deposit was investigated using centrifuge tests [16]. The results showed that the magnitude of footing settlement could be reduced by increasing depth of treatment beneath the footing, however with the adverse effect of increasing the peak footing acceleration.

Centrifuge model and field case history information was not available on the performance of deep foundations situated in improved ground zones during earthquake loading and liquefaction. Further research was needed on the performance of deep foundations in liquefiable soil deposits and the benefits of using ground improvement to reduce the risk of damage on deep foundations, particularly in areas prone to lateral spreading [14].

The objective of this paper is to determine the range and effect of ground treatment for existing pile foundations situated in treated soils with liquefaction potential for retrofitting countermeasure. Results of the study can be used as a reference for decision-making or design practice. The computation software used for this study is the FLAC 2D (version 4.0), developed by Itasca Inc., USA. Because the behavior of pile foundation studied herein is in essence a result of a complicated soil-structure interaction and the deformation of interest depends on applied earthquake force and ground condition, the following assumptions were made for that the physical realities can be described with appropriate simplification:

1) During the earthquake, the pile foundation is subject to the same applied force before and after the soil liquefaction.

2) The residual strength of the liquefied soil is a constant and independent of time.

3) The displacements of the pile and the surrounding soils are continuous and compatible. 
4) The soils are homogeneous and isotropic, linear elastic, and perfectly plastic before and after liquefaction, and after ground treatment.

Results. A realistic pile foundation located in eastern Japan was studied in this paper. The on-site soils consist primarily of silty sand (SM) and silty clay (CL). The simplified soil profile and parameters are listed in Table 1 . The peak ground acceleration (PGA) is $0.34 \mathrm{~g}$, and the groundwater table is about $0.1 \mathrm{~m}$ below the ground surface.

Table 1. Summary of soil parameters used for the case study

\begin{tabular}{|c|c|c|c|c|c|c|c|c|c|}
\hline $\operatorname{Depth}(m)$ & Thick(m) & $\begin{array}{l}\text { USCS } \\
\text { Classification }\end{array}$ & $\begin{array}{l}\text { SPT- } \\
N\end{array}$ & $\begin{array}{l}\gamma_{t} \\
\left(\mathrm{~kg} / \mathrm{m}^{3}\right)\end{array}$ & $\begin{array}{l}s_{u} \\
\left(k g / m^{2}\right)\end{array}$ & $\begin{array}{l}\phi^{\prime} \\
(9)\end{array}$ & $\begin{array}{l}E \\
(G P a)\end{array}$ & $v$ & $\begin{array}{l}\text { Reduction } \\
\text { factor }\end{array}$ \\
\hline 10.1 & 10.1 & SM & 10 & 2020 & & 31.0 & 17.10 & 0.3 & $1 / 3$ \\
\hline 20.6 & 10.5 & SM & 19 & 1970 & & 31.5 & 33.66 & 0.3 & $2 / 3$ \\
\hline 23.6 & 3.0 & $\mathrm{CL}$ & 15 & 1900 & 7300 & & 14.60 & 0.495 & 1 \\
\hline 29.6 & 6.0 & $\mathrm{CL}$ & 11 & 1920 & 8600 & & 17.20 & 0.495 & 1 \\
\hline 49.1 & 19.5 & $\mathrm{CL}$ & 18 & 1880 & 10600 & & 21.20 & 0.495 & 1 \\
\hline 56.6 & 7.5 & SM & 27 & 2000 & & 30.5 & 48.96 & 0.3 & 1 \\
\hline 61.1 & 4.5 & SM & 64 & 2180 & & 32.5 & 114.66 & 0.3 & 1 \\
\hline 72.6 & 11.5 & SM & 49 & 2050 & & 31.0 & 88.02 & 0.3 & 1 \\
\hline
\end{tabular}

The results of liquefaction hazard assessment using "Assessment of Liquefaction Potential" [4] and "Evaluation of Liquefaction Index" [17] showed that the sandy soil layers within 20.6m from ground surface had low to medium liquefaction potential, and the associated reduction factors were respectively 0.33 and 0.67, referred to Akin et al. (2011)[4]. During liquefaction, the maximum lateral displacement of $2.2 \mathrm{~cm}$ at top of foundation piles is expected, and the shearing stresses exceed the shearing resistance of pile.

In the analysis, high pressure jet grouting is assumed as the retrofitting measure of ground treatment, and the allowable lateral displacement of foundation piles is $1.66 \mathrm{~cm}$ in the original design requirement of pile to avoid shearing failure during liquefaction in the surrounding soils of improved ground.

The original analysis and design for the pile group were performed using the Group software (version 3.0), developed by Ensoft Inc., USA. For the case study, we used the FLAC software in stead to estimate range of ground treatment, and the displacement compatible principle was used in the analysis to bridge over the commercial softwares, FLAC and Group, for the analysis of pile foundation and effectiveness of ground improvement. Using FLAC, we simulate and determine the range of treated zone by changing the soil parameters in local treated region while satisfying the same displacement between pile head and pile cap analyzed by Group and FLAC, respectively.

The analysis procedure is illustrated as follows:

1) Using maximum lateral displacement as the control factor, the simulation was completed when the displacements of pile cap and pile head obtained from FLAC and Group, respectively, are identical.

2) The activity forces applied to soil layers came from parts of pile cap and pile. The pile cap was assumed as a rigid body, so its lateral displacement was same as the pile head. By using the lateral displacement of soils before ground treatment, in the seismic situation, analyzed by Group for checking, the distribution of applied forces on pile foundation used as an initial condition in FLAC was calibrated with the displacement compatible principle of which the associated displacement field of pile foundation must be identical to that obtained from Group analysis.

3) By conducting a parametric study for a treated zone based on the consideration of post ground treatment and seismic state, and numerically simulating soil displacements with input forces as indicated above. Until the simulated lateral displacement is identical to the results obtained from Group, the improvement zone (i.e. zone with soil parameters changed) can be identified. 
According to the statements mentioned above, the analytical scheme and the results are described as below:

1) Set up the semi-infinite numerical mesh $(\mathrm{X} 68 \times \mathrm{Y} 58)$, according to soil profiles and characteristics as shown on Table 1, and assign corresponding soil parameters to corresponding soil region, respectively. Mohr-Column model as the failure criterion is considered, and the scale unit is in KMS system (Fig. 1).

2) The maximum lateral displacement of pile group obtained from the analysis of Group, prior to ground improvement in seismic conditions, is simplified as the control soil displacement curve (Fig. 2).

3) Assuming that the displacement of pile cap $\left(s_{c a p}\right)$ is equal to the displacement of pile head $\left(s_{\text {pile }}\right)$ gained from Group, and then the applied forces can be obtained with iteration until the $s_{c a p}$ is identical to $s_{\text {pile }}$ for this particular case (Fig. 3 and Fig. 4). Results of the computed maximum displacement for pile group (with pile cap) subjected to simulated lateral forces are in agreement with each other between Group and FLAC in the liquefaction without ground treatment state.

4) With the applied forces mentioned above, the liquefaction conditions with treated ground, and the treated strength shown as undrained shear strength, $s_{u}$, the improvement zone can be obtained by iteration until the maximum lateral displacement is almost identical to that obtained from Group (Fig. 5 and Fig. 6).

The strength reduction from liquefaction generally causes increased lateral displacements. The less allowable lateral displacements of piles are, the larger the range of improvement zone is. Results of the computed maximum lateral displacements of pile group (with pile cap) subjected to simulated lateral forces are in agreement with each other between Group and FLAC in the liquefaction with ground treatment state.

Results of analysis in this case study showed that the treated range was considerably large when the treated strength was equal to $12500 \mathrm{~kg} / \mathrm{m}^{2}$ in improvement zone, with width, $\mathrm{W}=15.7 \mathrm{~m}$, and depth, $\mathrm{D}=7 \mathrm{~m}$. The improvement zone is identified and the displacement vectors of improved zone has upward potential after ground treatment.

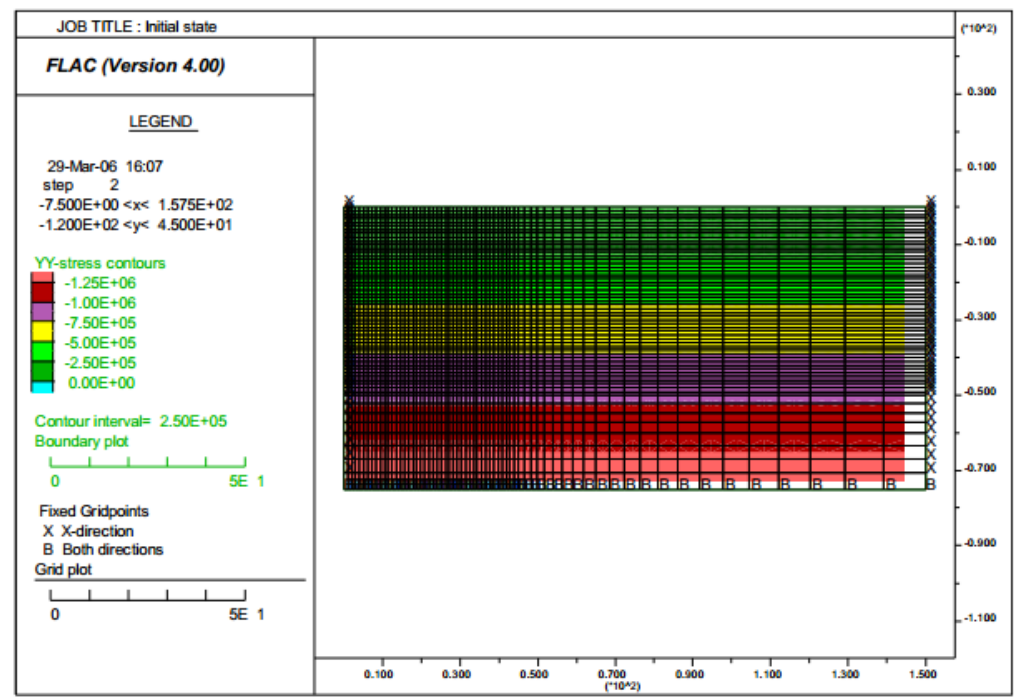

Fig. 1. The initial state of the finite difference mesh generated with FLAC grid 


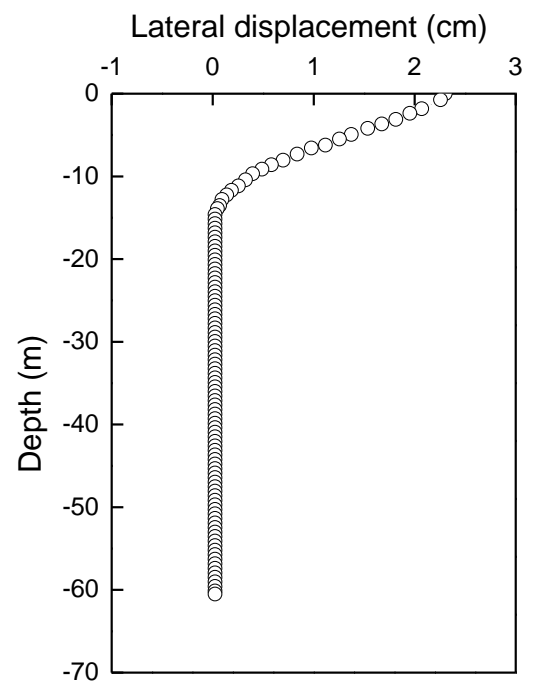

Fig. 2. The maximum lateral displacement of pile group computed by Group.

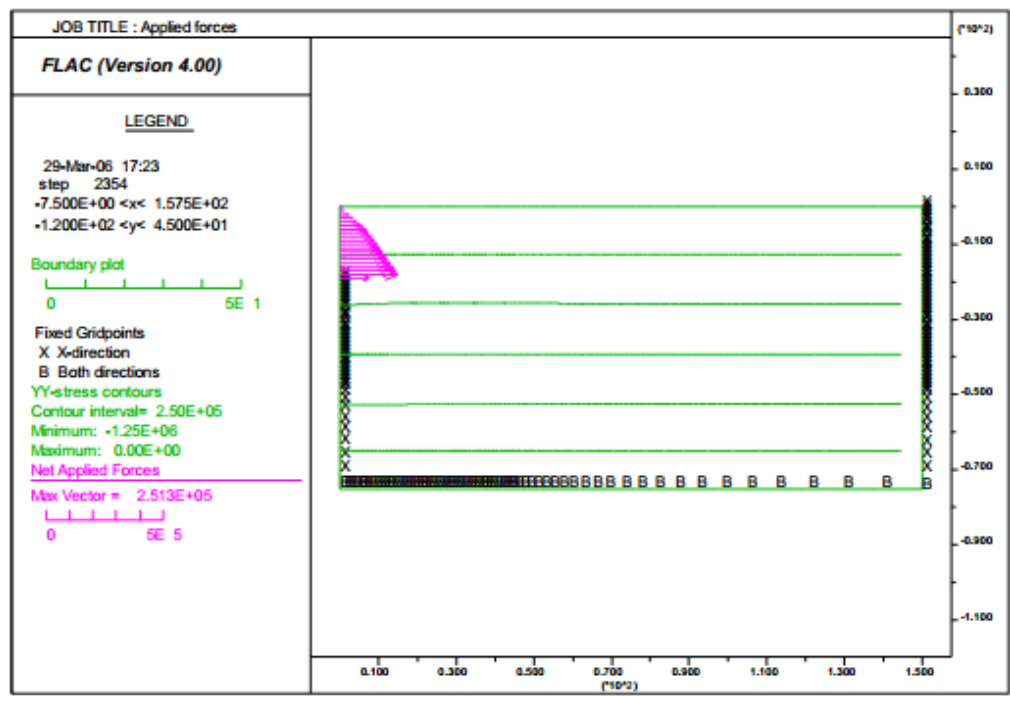

Fig. 3. The applied forces gained to analyze the case being studied (Liquefaction without ground treatment).

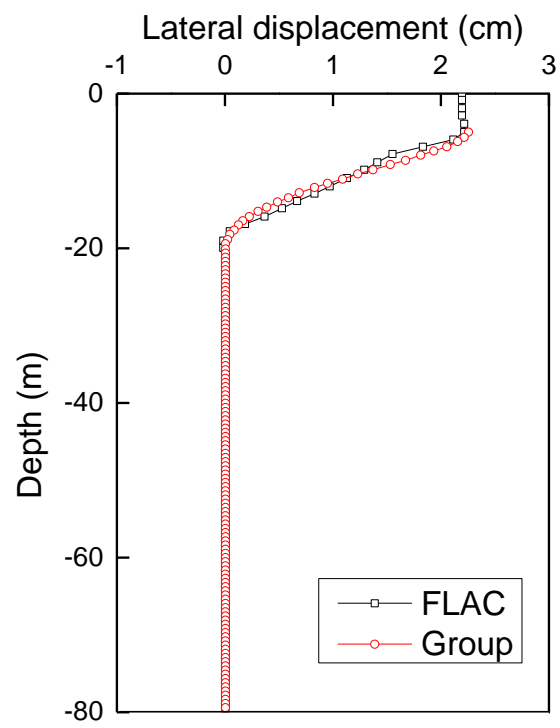

Fig. 4. Maximum displacement for pile group (with pile cap) subjected to simulated lateral forces. 


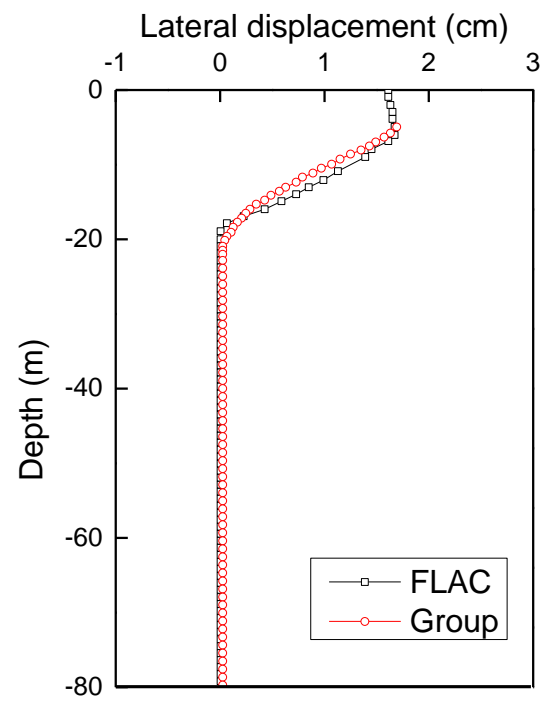

Fig. 5. Maximum lateral displacements of pile group (with pile cap) subjected to simulated lateral forces.

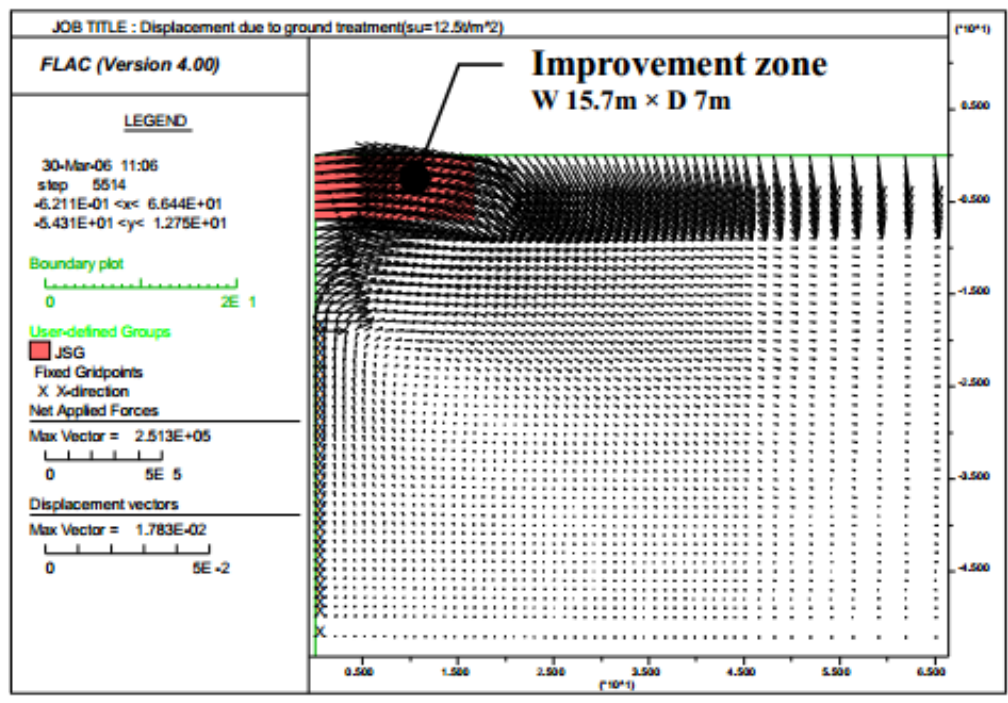

Fig. 6. Improvement zone.

Discussion. The following statements can be concluded from the analysis results stated above:

1) When soils were liquefied, the displacement vectors of soils around the pile group exhibited downward movement (Fig.7), which was in agreement with liquefaction phenomenon in practice, where the ground settlements were observed in liquefied soils.

2) When soils were subject to lateral forces, the displacements in vertical direction could be developed. With the same treated strength and constant treated width, the vertical displacements of soils around the pile group would change from settlement into dilation with the increasing treated

depth gradually, which agreed with real soil behavior in the same situation. In other words, only horizontal displacement would be developed when the treated depth increased to some critical value (Fig. 8). When the treated depth was insufficient, the improvement zone would sink, i.e. the treated effect would not be suitable.

3) With the same treated strength and constant treated depth, the horizontal displacement and vertical displacement decrease with the increasing treated width gradually (Fig.9). However, because the 
strength of soil in the improvement zone was higher than the unimproved liquefied soil underneath, the soils around the improvement zone still settle and the treated effect would be limited.

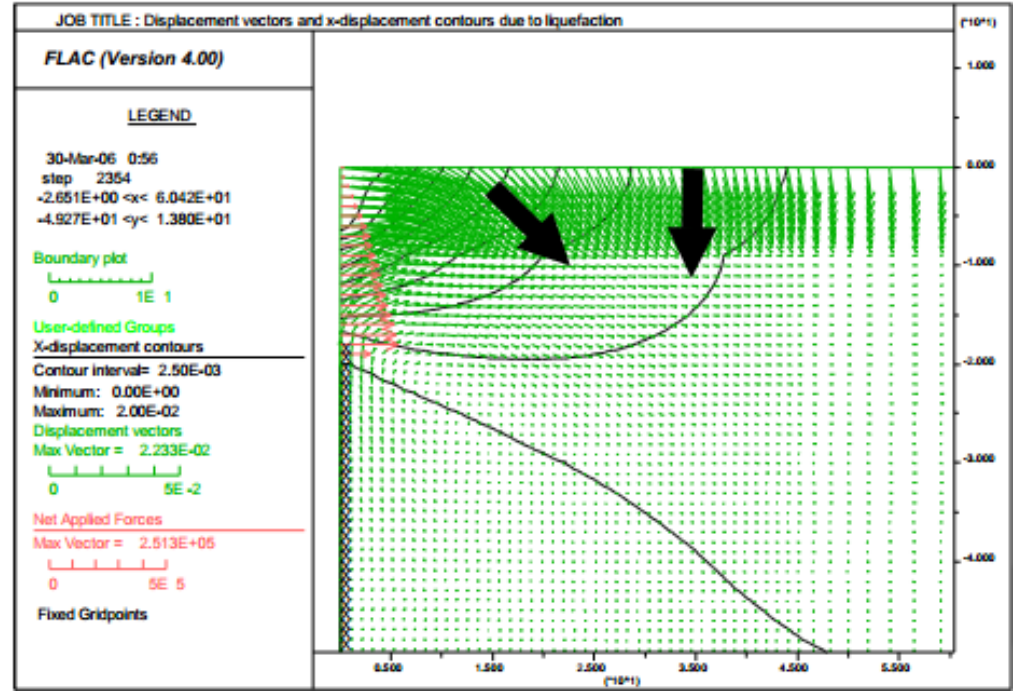

Fig. 7. Liquefaction induced soil settlements associated with downward potential as implied by the displacement vectors.

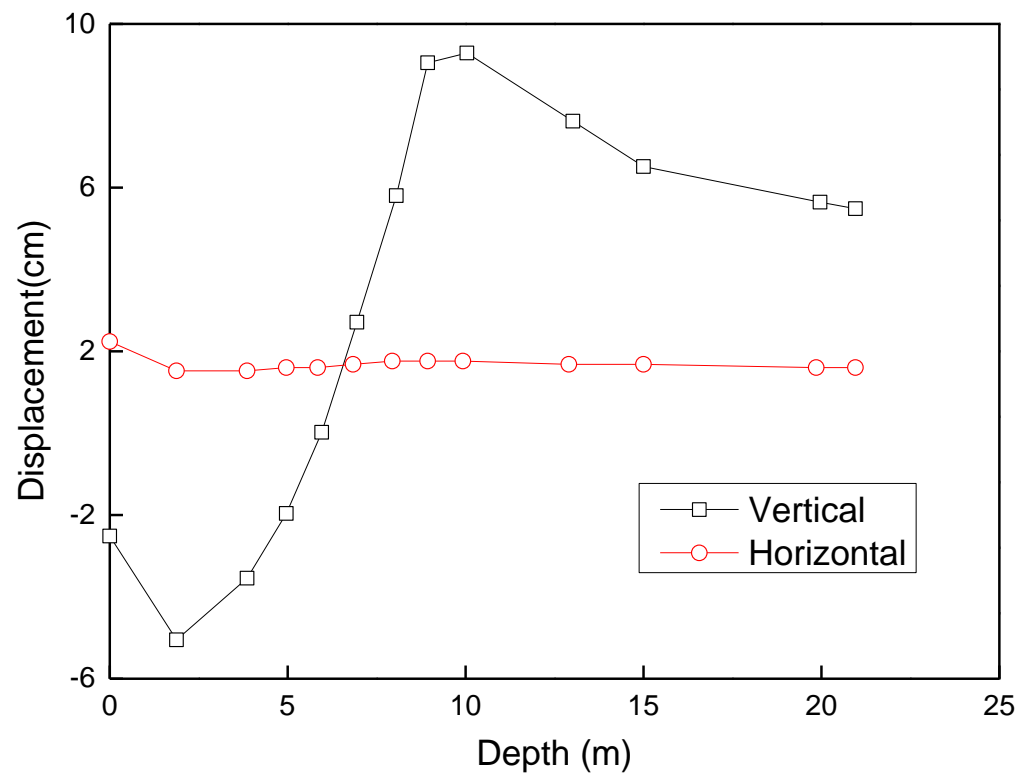

Fig. 8. The computed displacements verse the depth of the improvement zone at a constant treated width of $15.7 \mathrm{~m}$. 


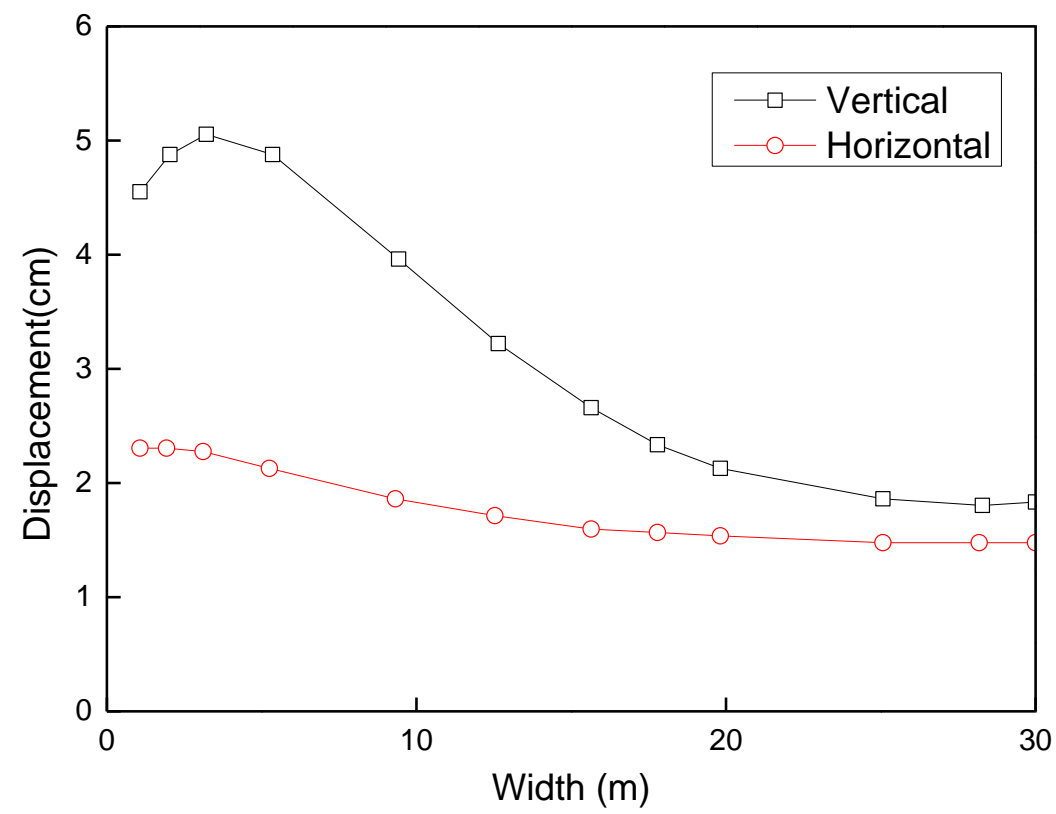

Fig. 9. The computed displacements verse the width of the improvement zone at a constant treated depth of $7 \mathrm{~m}$.

Summary. According to the study above, if simply consideration of effect of ground treatment, the suggestion to determine the range of improvement zone is that to assume the treated depth, which not more than depth of liquefiable soils, and then to decide the smallest treated width satisfied with design treated strength and vertical displacement, which not less than zero in the bottom of improvement zone.

If consideration of adopting ground treatment to increase soil shear resistance in order to avoid shear failure of existing piles, the suggestion is that to determine design demands in terms of treated depth and treated strength, then to decide treated width of the improvement zone incorporating with the control of allowable lateral displacement of pile. Besides, it is need to recheck vertical displacement such that it is no less than zero.

Although the effect of ground treatment in resistance of displacement is effective, but the corresponding cost is significant, most of the time the ground treatment countermeasure is not agreed by the client. Unless the other retrofitting measures are not working, the ground treatment would be limited to unformed countermeasure, and it is an inevitable problem in construction practice.

\section{Reference}

[1] Tokimatsu K, Tamura S, Suzuki H, et al. Building damage associated with geotechnical problems in the 2011 Tohoku Pacific Earthquake. Soils and Foundations, 2012, 52(5): 956-974.

[2] Bolton Seed H, Tokimatsu K, Harder L F, et al. Influence of SPT procedures in soil liquefaction resistance evaluations. Journal of Geotechnical Engineering, 1985, 111(12): 1425-1445.

[3] Tokimatsu K, Yoshimi Y. Empirical correlation of soil liquefaction based on SPT N-value and fines content. Soils and Foundations, 1983, 23(4): 56-74.

[4] Akin M K, Kramer S L, Topal T. Empirical correlations of shear wave velocity (Vs) and penetration resistance (SPT-N) for different soils in an earthquake-prone area (Erbaa-Turkey). Engineering Geology, 2011, 119(1): 1-17.

[5] Stark T D, Olson S M. Liquefaction resistance using CPT and field case histories. Journal of Geotechnical Engineering, 1995, 121(12): 856-869.

[6] Juang C H, Yuan H, Lee D H, et al. Simplified cone penetration test-based method for evaluating 
liquefaction resistance of soils. Journal of geotechnical and geoenvironmental engineering, 2003, 129(1): 66-80.

[7] Smith R E. Prefab architecture: A guide to modular design and construction. John Wiley \& Sons, 2011.

[8] Nutt R V. Improved Seismic Design Criteria for California Bridges: Provisional Recommendations. 1996.

[9] Finn W D L. 1st Ishihara Lecture: An overview of the behavior of pile foundations in liquefiable and non-liquefiable soils during earthquake excitation. Soil Dynamics and Earthquake Engineering, 2015, 68: 69-77.

[10] Turner B J, Brandenberg S J, Stewart J P. Case Study of Parallel Bridges Affected by Liquefaction and Lateral Spreading. Journal of Geotechnical and Geoenvironmental Engineering, 2016: 05016001.

[11] Zekri A, Ghalandarzadeh A, Ghasemi P, et al. Experimental study of remediation measures of anchored sheet pile quay walls using soil compaction. Ocean Engineering, 2015, 93: 45-63.

[12] Huang Y, Wen Z. Recent developments of soil improvement methods for seismic liquefaction mitigation. Natural Hazards, 2015, 76(3): 1927-1938.

[13] Adalier K, Elgamal A W, Martin G R. Foundation liquefaction countermeasures for earth embankments. Journal of Geotechnical and Geoenvironmental Engineering, 1998, 124(6): 500-517.

[14] Cooke H G, Mitchell J K. Guide to Remedial Measures for Liqufaction Mitigation at Existing Highway Bridge Sites. Buffalo, New York, 1999.

[15] Hatanaka M, Suzuki Y, Miyaki M, et al. Some factors affecting the settlement of structures due to sand liquefaction in shaking table tests. Soils and Foundations, 1987, 27(1): 94-101.

[16] Liu L, Dobry R. Seismic response of shallow foundation on liquefiable sand. Journal of geotechnical and geoenvironmental engineering, 1997, 123(6): 557-567.

[17] Iwasaki T, Arakawa T, Tokida K I. Simplified procedures for assessing soil liquefaction during earthquakes. International Journal of Soil Dynamics and Earthquake Engineering, 1984, 3(1): 49-58. 